\title{
O olhar multifacetado dos Laços de família, de Clarice Lispector
}

\author{
Adriana Carina Camacho Álvarez*
}

\begin{abstract}
Resumo: A questão do olhar ocupa, no universo de Clarice Lispector, um lugar de indiscutível destaque, pois, através dele, a autora ensaia, em toda a sua obra, o deflagrar de uma realidade que subjaz à nossa percepção habitual das coisas. Trata-se de um olhar, em princípio, de dupla direção: da personagem para o mundo e deste, a modo de espelho, para o interior da personagem, passando por seu corpo. Ao encontrar o leitor, porém, esse olhar atinge um alcance ilimitado. Instância intermediária entre o indivíduo e o mundo exterior, o olhar serve, nos contos de Laços de família, como ponte entre a história mais superficial e a verdadeira história que está sendo narrada, a da batalha existencial da personagem. Assim, ele transforma-se em um dos principais recursos expressivos de uma linguagem que, como poucas, procura acompanhar os meandros da alma humana.
\end{abstract}

Palavras-chave: conto; intimismo; olhar; fenomenologia

\begin{abstract}
In Clarice Lispector's universe, the matter of the look plays a role of undeniable importance. Throughout her entire work it is through the look that the author carries out the act of awakening to a reality that underlies our ordinary perception of things. At first it is about a doubly directed look: the character's towards the world and, as if it was a mirror, the world's towards the character's inner self, passing through her body. However, this look achieves an unlimited level when it reaches the reader. As an intermediary condition between the individual and the outer worlds, in Clarice Lispector's short stories the look serves as a "bridge" between a more superficial story and the true story that is being narrated, which deals with the character's existential struggle. Thus, this look turns into one of the main expressive resources of a language which, as only a few do, tries to look into the human soul's peculiarities.
\end{abstract}

Keywords: short story; intimism; look; phenomenology

Tanto em pintura como em música e literatura, tantas vezes o que chamam de abstrato me parece apenas o figurativo de uma realidade mais delicada e mais difícil, menos visível a olho nu.

Clarice Lispector

\section{Clarice Lispector e o conto de atmosfera}

Clarice Lispector ocupa, inevitavelmente, um lugar de destaque em qualquer estudo ou resenha sobre a história do conto no Brasil por ser considerada uma das principais

\footnotetext{
* Adriana Carina Camacho Álvarez é tradutora do Português pela Universidade da República - Uruguai. É Mestre em Literatura Brasileira pela UFRGS e doutoranda pela mesma Instituição. Em suas publicações destacam-se: "Água viva de Clarice Lispector: a arte como instrumento de resgate do Ser". Anais do XXIII Seminário Brasileiro de Crítica Literária da PUCRS; "La escena de la ley”, Enrique Kozicki. Tradução para o português, “A cena da lei”, Editora UFSM, no prelo
} 
representantes e, em parte, introdutora de uma nova modalidade de conto, por muitos autores denominado "conto de atmosfera". Essa modalidade de conto apresentaria a particularidade de ser em profundidade, não em extensão (embora continue a apresentar uma boa dose de linearidade que lhe confere certo começo, meio e fim), adaptando-se a ele com peculiar pertinência a aproximação que realiza Cortázar (1974, p. 151-152) entre conto e fotografia, em sua tentativa de definir alguns aspectos da narrativa curta. Conforme o contista argentino, o conto - como a fotografia - opera um recorte limitado da realidade, mas que contém em si uma amplidão que transcenderia esse limite, à maneira de uma janela aberta. Ora, se quisermos fazer uma analogia com os contos de Clarice, teremos que imaginar a câmera utilizada pelo fotógrafo como munida de uma lente com um zoom potente o suficiente para permitir-nos uma aproximação quase ad infinitum do mundo interior de uma determinada personagem. No final, porém, o fotógrafo escolheria voltar, muitas vezes, à "paisagem", ao quadro original.

O conto de atmosfera seria, assim, uma narrativa na qual a ênfase não estaria colocada no desenrolar de determinadas circunstâncias ou acontecimentos externos que dariam forma a uma situação específica, mas sim na repercussão que esses fatos suscitam nas personagens que os percebem e, a partir dessa percepção, neles se envolvem. Isso termina criando um determinado ambiente psicológico (e somático), marcado por uma tensão permanente, que constitui, enfim, o traço salientado pela denominação assinalada, o caráter de "atmosfera".

Em função dessas características, nessa modalidade de conto, produz-se um deslocamento dos fatos banais ou cotidianos que passam a ocupar um segundo plano da narração. Isso não quer dizer que eles desapareçam. Pelo contrário, subsistem, conformando uma moldura perfeita para a fotografia de Cortázar. No entanto, o que ganha a categoria de destaque (isto é, o primeiro plano) é a descrição pormenorizada dos diferentes estados de espírito e dos processos psicológicos e/ou somáticos vividos pelas distintas personagens. E é, com efeito, a temática existencial a que interessa a Clarice Lispector, as contradições e os conflitos que acompanham todo ser humano em sua busca de um sentido para a vida. É como se a segunda história de todo conto da qual fala Ricardo Piglia (1994, p. 37-38), em seu Laboratório do Escritor, usurpasse o lugar da primeira, sem, por isso, substituí-la por completo. 


\section{0 olhar clariceano}

Todas essas características, no caso da autora que nos ocupa neste ensaio, são acompanhadas por um estilo muito particular de narrar. E um dos recursos mais utilizados pela escritora para atingir esse tipo de narração intimista é um uso específico e muito particular do olhar. O olhar se comporta em alguns contos de Clarice Lispector como um diamante em face a um espelho, cujo reflexo não apenas volta ao próprio diamante, mas atinge diferentes corpos, inclusive - se suficientemente envolvido - o do próprio leitor.

Nesse sentido, não deixa de ser significativo que o espelho seja uma presença constante em Laços de família. O espelho reflete em seus contos não uma realidade objetiva, mas uma imagem que, em grande medida, decorre das intenções de quem está a olhar-se, geralmente à procura de uma aparência exterior tranquilizadora e/ou cúmplice. É o espelho quem confere alívio às personagens Ana e Laura dos contos "Amor" e "A imitação da rosa" respectivamente, quando, após terem se sobreposto a um perigoso desequilíbrio, constatam: "E se atravessara o amor e o seu inferno, penteava-se agora diante do espelho, por um instante sem nenhum mundo no coração. Antes de se deitar, como se apagasse uma vela, soprou a pequena flama do dia" (LISPECTOR, 1998, p. 29).

Interrompendo a arrumação da penteadeira, Laura olhou-se ao espelho: e ela mesma, há quanto tempo? Seu rosto tinha uma graça doméstica, os cabelos eram presos com grampos atrás das orelhas grandes e pálidas. Os olhos marrons, os cabelos marrons, a pele morena e suave, tudo dava a seu rosto já não muito moço um ar modesto de mulher (LISPECTOR, 1998, p. 35).

Por sua vez, o adolescente protagonista de "Começos de uma fortuna" sorri satisfeito ao corroborar no espelho que as verdadeiras razões de seu mal-estar ficavam ocultas atrás de uma aparência de moço bem comportado (que os olhos, por sua vez, desmentiam).

Esse olhar primário gera, de fato, múltiplos olhares sobre o resto do mundo e sobre si. Ele vem sendo prenunciado por certos relances prévios, indícios dessa segunda história subterrânea à narração mais exterior, até realizar-se na forma de uma explosão epifânica (que passa a ser o centro do conto), conclusão de um determinado processo de tensão anterior de que nós, leitores, apenas chegamos a ter alguns sinais esparsos.

É como se os contos de Clarice funcionassem como a psique humana, muitas vezes impulsionada por motivos ocultos do inconsciente que acabam, em um determinado momento, revelando-se na superfície em toda sua crua intensidade. De fato, poderíamos chamar os indícios referidos no parágrafo anterior de "lapsos comportamentais". Por exemplo, a personagem Ana, do conto "Amor", antes de seu encontro com o cego, já 
pressentia algum perigo a uma determinada hora da tarde: "Certa hora da tarde as árvores que plantara riam dela. Quando nada mais precisava de sua força, inquietava-se" (LISPECTOR, 1998, p. 19).

As personagens, sem o saberem, encontram-se em uma constante busca promovida por uma permanente sensação de insatisfação, busca que acaba desencadeando a explosão através de um determinado olhar revelador. Este, por sua vez, não é mais do que o resultado dessa mesma busca. Assim, o mecanismo propulsor de toda essa revolta interna, de toda essa crise existencial é, na maioria das vezes, acionado pelo olhar. O conto mencionado no parágrafo anterior mostra claramente a fragilidade desse falso equilíbrio humano:

Ela apaziguara tão bem a vida, cuidara tanto para que esta não explodisse. Mantinha tudo em serena compreensão, separava uma pessoa das outras, as roupas eram claramente feitas para serem usadas e podia-se escolher pelo jornal o filme da noite - tudo feito de modo a que um dia se seguisse ao outro. E um cego mascando goma despedaçava tudo isso (LISPECTOR, 1998, p. 23).

O olhar se detém em um objeto, um fato ou uma pessoa, que, inerte e carente de qualquer vontade, devolve esse olhar, repercutindo na personagem (fonte do olhar), de forma direta e implacável, revelando-o. Isto é evidente em vários contos do livro analisado. Por exemplo, quando a protagonista de "Devaneio e embriaguez de uma rapariga" vê um quadro em um restaurante onde vai jantar, o mesmo acaba revelando-lhe uma sensibilidade inédita que deixa em evidência sua realidade medíocre e rotineira, carente de qualquer sentido mais elevado.

O mesmo acontece com a personagem Ana, do conto “Amor". Dessa vez, porém, quem revela à personagem sua existência artificial é (não paradoxalmente) um cego. $\mathrm{Na}$ verdade, esse cego acaba virando um verdadeiro espelho (não mais um espelho tranqüilizador) para a protagonista do conto, que descobre que vivia sem ver a vida, deixandose apenas levar por regras e rituais que a mantinham em uma verdadeira morte. A partir desse encontro com o cego (com ela mesma) e da crise existencial então acionada, ela começa lentamente a redescobrir tudo o que tinha perdido com seu casamento e a sentir uma espécie (bem particular) de piedade por ela mesma. No final, embora acabe fatalmente voltando para a mesma situação, tudo muda, pois Ana passa a ter consciência (uma consciência definitiva) da prisão na que se encontra e da enorme dificuldade e do perigo que uma pretensa fuga acarretaria. É assim que ela exprime esse momento de tomada de consciência:

Com horror descobria que pertencia à parte forte do mundo - e que nome se deveria dar a sua misericórdia violenta? Seria obrigada a beijar o leproso, pois nunca seria apenas sua irmã. Um cego me levou ao pior de mim mesma, pensou espantada. Sentia-se banida porque nenhum pobre beberia água nas suas mãos ardentes (LISPECTOR, 1998, p. 27). 
Dessa forma, tem lugar uma dupla objetivização: da pessoa fonte do olhar em relação ao objeto e de este para a primeira. E como nós, leitores, somos levados pelo narrador a "ver" as coisas através desse olhar, ficando presos a ele sem praticamente nenhuma liberdade de discernimento, à medida que somos tomados pelo conto, também somos atingidos por esse reflexo revelador. Por isso, é sempre um olhar em mais de duas direções. Afinal, como pertinentemente afirma Cátia Castilho Simon:

Ao contrário do esperado, quando nos deparamos simplesmente com um nome de personagem, sem biografia, nem os traços exteriores, sentimos que os procedimentos de construção das personagens são tentativas empreendidas por Clarice a fim de comunicar-se com nossa intimidade, com o mais recôndito e profundo de nós mesmos (SIMON, 1999, p. 330).

Com efeito, ao ler um conto de Clarice, amiúde somos capturados pela visão da personagem central focalizadora da narrativa, apenas nos apercebendo desse fato quando, por uma circunstância qualquer dentro do relato, o narrador resolve introduzir outra personagem, uma visão diferente (muitas vezes através de um diálogo corriqueiro). Para conseguir esse efeito, Clarice se vale muito principalmente de dois recursos: a oscilação constante entre a primeira e a terceira pessoa do singular (embora predominando sempre a última), é o que o filósofo Bakhtin (1986, p. 123) chamava de discurso direto impessoal (isto é, o discurso indireto livre), uma forma de introduzir a voz do outro no discurso do narrador através do uso de um certo estilo de linguagem, de uma expressividade, que seria própria do personagem e não da instância narrativa. Vejamos um exemplo deste segundo procedimento:

Mas, com as rosas desembrulhadas na mão ela esperava. Não as depunha no jarro, não chamava Maria. Ela sabia por quê. Porque devia dá-las. Oh ela sabia por quê.

E também porque uma coisa bonita era para se dar ou para se receber, não apenas para se ter. E, sobretudo, nunca para se "ser". Sobretudo nunca se deveria ser a coisa bonita. A uma coisa bonita faltava o gesto de dar. Nunca se devia ficar com uma coisa bonita, assim, como que guardada dentro do silêncio perfeito do coração (LISPECTOR, 1998, p. 47).

Em função desta escolha narrativa (predominante na obra de Clarice Lispector como um todo), no caso da autora de Laços de família, nunca poderíamos falar de um narrador confiável. Longe de qualquer objetividade, seu narrador sempre acaba apagando-se, ao imiscuir-se indissoluvelmente na perspectiva de uma certa personagem, dando uma visão extremamente subjetiva dos fatos. Desta forma, o narrador acaba confundindo-se, em boa medida, com as personagens. Isso dá lugar a uma problematização do papel do narrador, que levaria Benedito Nunes (1989), por exemplo, a definir o estilo narrativo de Clarice Lispector utilizando o termo híbrido "conficção", e a alguns autores a considerar esse tipo de escrita como, em última instância, não mais do que um reflexo da consciência de si do(a) próprio(a) autor(a). 
De fato - e para além de um biografismo simplista - parece inegável que a visão de mundo de Clarice está muito presente em seus contos, sendo possível detectar neles, inclusive, muitas vezes, claros dados autobiográficos. Por isso, por exemplo, não é surpreendente que ela mesma tenha pensado em sua própria avó quando lhe perguntaram a origem daquela personagem por ela criada, a aniversariante de "Feliz Aniversário".

Continuando com as reflexões pertinentes ao uso do olhar em Laços de família, cabe destacar também que, nesta obra, as personagens vêem um corpo e vêem "seu" corpo, pois que o reflexo repercute nelas até mesmo fisicamente. E o leitor também não fica completamente imune a essa possibilidade. O olhar clariceano sempre supõe um contato, um encontro e uma descoberta. Por isso, a protagonista de "Preciosidade" sabe perfeitamente que, para evitar transformar-se em mulher, deveria evitar o olhar dos outros, olhar que, fatalmente, obrigá-la-ia a enfrentar esse doloroso ritual de passagem, ao revelá-la sem concessões:

\footnotetext{
Tudo isso aconteceria se tivesse a sorte de "ninguém olhar para ela". [...]

Mas também de rapazes tinha medo, medo também de meninos. Medo que lhe "dissessem alguma coisa", que a olhassem muito. [...]

Nesta hora em que o cuidado tinha que ser maior, ela era protegida pela espécie de feiúra que a fome acentuava. [...]

Não deveria ter visto. Porque, vendo, ela por um instante arriscava-se a tornar-se individual, e também eles (LISPECTOR, 1998, p. 82, 83, 85 e 89).
}

Às vezes esse olhar é guiado pela vontade, mas sem nunca perder seu caráter revelador e surpreendente, como em "O búfalo". Com efeito, a protagonista desse conto vai ao Jardim Zoológico procurar, entre os animais, aquele que lhe ensine a odiar o suficiente para conseguir fazer o que devia fazer e não podia: matar-se e assim matar seu amor. E termina encontrando esse ódio no búfalo, mas não porque o búfalo encerre esse sentimento em si, mas porque ela, através do olhar do búfalo (e de sua inicial indiferença), consegue, ao objetivá-lo, atualizar o seu drama, sentindo toda a dor que finalmente lhe dá forças para cometer o seu “crime”. Tanto é assim que só no instante em que ela vai escorregando pela grade, ao morrer, já quase sem consciência, é que consegue ver simplesmente "um búfalo" (indeterminado). De fato, a intencionalidade é o que explica que existam objetos, ao ser "a evidência o modo originário da intencionalidade, isto é, o momento da consciência em que a própria coisa de que se fala se dá em carne e osso, em pessoa, à consciência, em que a intuição é preenchida" (LYOTARD, 1986, p. 40).

Muitas vezes, o olhar de um sujeito que se pretende de dominação, de superioridade, acaba conduzindo esse mesmo sujeito à condição de dominado, não sem um misto de surpresa. Isso é o que ocorre com o protagonista de "O crime do professor de matemática", que se vê obrigado a abandonar seu cachorro, pois o animal acabara virando afinal seu dono, 
ao lembrar-lhe o tempo inteiro, com seu olhar canino, a sua própria obrigação: a de ser humano e de limitar-se a (apenas) cuidar dele. Assim o narrador autodiegético sente a apelação que o cachorro lhe dirige desde sua inocência de cão:

$\mathrm{E}$, inquieto, eu começava a compreender que não exigias de mim que eu cedesse nada da minha [natureza] para te amar, e isso começava a me importunar. Era no ponto de realidade resistente das duas naturezas que esperavas que nos entendêssemos: Minha ferocidade e a tua não deveriam se trocar por doçura: era isso o que pouco a pouco me ensinavas, e era isto também que estava se tornando pesado. Não pedindo nada, me pedias demais. De ti mesmo, exigias que fosses um cão. De mim, exigias que eu fosse um homem. E eu, eu disfarçava como podia. Às vezes, sentado sobre as patas diante de mim, como me espiavas! Eu então olhava o teto, tossia, dissimulava, olhava as unhas. Mas nada te comovia: tu me espiavas (LISPECTOR, 1998, p. 112-123).

De fato, o que parece ficar claro mediante esse jogo do olhar é que nos formamos unicamente em nossa relação com o outro e só em virtude da mesma é que "somos". Só ao objetivar e ao ser objetivado é que sou: "Fica reafirmado pelos procedimentos de Clarice Lispector que, somos processo, incompletos, e que, portanto, necessitamos do outro para sermos deflagrados”(SIMON, 1990, p. 330).

E essa objetivização que dá lugar, de alguma forma, à própria existência, realiza-se, sobretudo, através do olhar. Diz Merleau-Ponty:

Cumpre que ele confesse [o pintor], como diz um filósofo, que a visão é espelho ou concentração do universo, ou que, como diz outro, o ídios kósmos, abre-se por meio dela para um koinòs kósmos, enfim, que a mesma coisa está lá no coração do mundo e cá no coração da visão, a mesma ou, se se fizer questão, uma coisa semelhante, porém segundo uma similitude eficaz, que é parenta, gênese, metamorfose do ser em sua visão (MERLEAU-PONTY, 1980, p. 91).

No conto "Uma galinha", e a fim de exprimir a insignificância do animal, o narrador não encontra expressão mais oportuna do que dizer que ela "não olhava para ninguém, ninguém olhava para ela” (LISPECTOR, 1998, p. 30), mostrando assim que, praticamente, não tinha existência real. O que acaba conferindo-lhe certa significação e inclusive importância dentro da casa é o olhar da família que, objetivando-a, passa a projetar nela sentimentos de ternura maternal comovente, totalmente alheios à própria galinha. Assim, “A galinha tornara-se a rainha da casa. Todos, menos ela, o sabiam” (LISPECTOR, 1998, p. 32).

Da mesma forma, o olhar confere certa legitimidade a uma ação. Por isso, o personagem Manoel, de "Feliz Aniversário", extremamente inseguro, não deixa nunca de procurar o olhar de sua mulher ou de seu irmão para validar tudo o que ele diz. É que o que não se olha parece nunca ter existido, ou pelo menos ter sido esquecido por completo. Por isso (a ausência de) o olhar pode prestar-se aos interesses da hipocrisia social, que oculta o que não é desejável mediante sua negação, como, por exemplo, a crise (loucura momentânea) de Laura em "A imitação da Rosa", que deve ser obliterada, esquecida: "As pessoas felizmente 
ajudavam a fazê-la sentir que agora estava ‘bem'. Sem a fitarem, ajudavam-na ativamente a esquecer, fingindo elas próprias o esquecimento como se tivessem lido a mesma bula do mesmo vidro de remédio" (LISPECTOR, 1998, p. 34-35). Também o fato de não olhar pode transformar-se em um claro sinal de desinteresse e/ou indiferença: "Antônio mal levantou os olhos do livro. A tarde de sábado sempre fora 'sua', e, logo depois da partida de Severina, ele a retomava com prazer, junto à escrivaninha” (LISPECTOR, 1998, p. 99).

Esse olhar institui-se, assim, em uma forma de (auto) conhecimento, não intelectual, mas sensorial, amiúde proposta no corpus dos próprios contos como a forma mais eficaz de atingir uma certa verdade visada. Em consonância com isso, o narrador de "Começos de uma fortuna", além de utilizar a expressão "visto que", que exprime uma conclusão lógica (e, por isso, em princípio, indiscutível), sintetiza da seguinte forma o estado de ânimo do garoto que está ensaiando seus primeiros passos de sua transformação em homem: "Mesmo agora, atravessando o pequeno portão, ele se tornara visivelmente mais moço e ao mesmo tempo menos criança, mais sensível e sobretudo sem assunto" (LISPECTOR, 1998, p. 107. Grifo nosso).

Esse conhecimento, assentado no olhar, é um saber - isto sim - enraizado na mais extrema subjetividade: passa pelo corpo, pela náusea, pelo estranhamento, sem necessariamente atingir uma inteligibilidade racional. Essa subjetividade se torna patente no conto "A menor mulher do mundo", em que diferentes pessoas, em face a um mesmo objeto, experimentam sensações e reações totalmente diversas, projetando nele diferentes intencionalidades.

Aponta Benedito Nunes em relação à náusea assinalada:

Manifestando-se como um mal-estar súbito e injustificável que do corpo se apodera e do corpo se transmite à consciência, por uma espécie de captação mágica emocional, a náusea (mais primitiva do que a angústia e como esporádica) revela, sob a forma de um fascínio da coisa, a contingência do sujeito humano e o absurdo do ser que o circunda (NUNES, 1989, p. 117).

Dentro de Laços de família existem muitas alusões e descrições minuciosas desse estado, mas consideramos o conto "O jantar" como o exemplo mais paradigmático, por ser justamente a náusea em si o grande centro do relato: "Meus olhos ardem e a claridade é alta, persistente. Estou tomado pelo êxtase arfante da náusea. Tudo me parece grande e perigoso" (LISPECTOR, 1998, p. 79).

De fato, a percepção é nossa primeira forma de conhecimento, “a percepção é aquilo por que estamos no mundo, ou aquilo por que temos um mundo, como quisermos, e constitui, por conseguinte, o núcleo de toda compreensão filosófica e psicológica do homem" (LYOTARD, 1986, p.61). Não podemos esquecer, afinal, que o que costumamos considerar 
real é, antes de tudo, o que podemos "ver", sendo que "a verdade (para nós) experimenta-se sempre e exclusivamente numa experiência atual" (LYOTARD, 1986, p. 41).

Mas essa percepção, na realidade, não se reduz exclusivamente à visão. Na verdade, é com todo o corpo que percebemos. Como diz Merleau-Ponty (1980, p. 93), "a interrogação da pintura visa a essa gênese secreta e febril das coisas em nosso corpo”. E só depois dessa percepção é que as coisas passam a nossa consciência, transformando-se em conhecimento de algum tipo. "Das coisas aos olhos e dos olhos à visão não passa nada mais que das coisas às mãos do cego e, das suas mãos, ao seu pensamento" (MERLEAU-PONTY, 1980, p. 95). É assim que a personagem Ana, do conto "Amor", reage ao descobrir novamente o mundo natural, reconhecendo sua sensualidade e brutalidade:

Ao mesmo tempo em que era imaginário - era um mundo de se comer com os dentes, um mundo de voluminosas dálias e tulipas. Os troncos eram percorridos por parasitas folhudas, o abraço era macio, colado. Como a repulsa que precedesse uma entrega - era fascinante, a mulher tinha nojo, e era fascinante.

As árvores estavam carregadas, o mundo era tão rico que apodrecia. Quando Ana pensou que havia crianças e homens grandes com fome, a náusea subiu-lhe à garganta, como se ela estivesse grávida e abandonada (LISPECTOR, 1998, p. 25).

E assim descobre Laura suas rosas:

Olhou-as com atenção. Mas a atenção não podia se manter muito tempo como simples atenção, transformava-se logo em suave prazer, e ela não conseguia mais analisar as rosas, era obrigada a interromper-se com a mesma exclamação de curiosidade submissa: como são lindas. [...]

Mas, sem saber por quê, estava um pouco constrangida, um pouco perturbada. Oh, nada demais, apenas acontecia que a beleza extrema incomodava" (LISPECTOR, 1998, p. 43).

E, seguindo o caminho inverso, "não há visão sem pensamento. Mas não basta pensar para ver: a visão é um pensamento condicionado; nasce 'por ocasião' daquilo que sucede no corpo, é 'excitada' a pensar por ele” (MERLEAU-PONTY, 1980, p. 99).

$\mathrm{E}$, de fato, é muito fácil constatar nos contos de Clarice esse percurso do olhar ao corpo e deste, através da visão, ao pensamento/reflexão ou à intuição. No conto "O jantar", por exemplo, o moço, perante a visão de um velho comendo, vai passando por diferentes sensações físico-emocionais até experimentar a náusea e terminar com a seguinte reflexão:

Mas eu sou homem ainda. Quando me traíram ou assassinaram, quando alguém foi embora para sempre, ou perdi o que de melhor me restava, ou quando soube que vou morrer - eu não como. Não sou ainda esta potência, esta construção, esta ruína. Empurro o prato, rejeito a carne e seu sangue (LISPECTOR, 1998, p. 80-81).

Não por acaso o estrabismo, a miopia, a cegueira são constantes na obra de Clarice. Falam, talvez, de um olhar que transcende os olhos, um olhar do fundo do espírito humano, capaz de viajar no passado através da lembrança e de prolongar-se no futuro através do sonho e da imaginação. Assim, a protagonista de "Devaneio e embriaguez de uma rapariga" "teve a 
visão de seu sorriso claro de rapariga ainda nova, e sorriu mais fechando os olhos, a abanar-se mais profundamente" (LISPECTOR, 1998, p. 9-10).

Já o que a personagem Cordélia, de "Feliz aniversário", vislumbra é seu terrível destino, ao olhar para a velha Anita: "Cordélia olhou-a espantada. O punho mudo e severo sobre a mesa dizia para a infeliz nora que sem remédio amava talvez pela última vez: É preciso que se saiba. É preciso que se saiba. Que a vida é curta. Que a vida é curta" (LISPECTOR, 1998, p. 64).

A imagem do diamante também ilustra um outro uso que Clarice faz do olhar: através dos diferentes olhares vai mostrando as diferentes faces do ser humano, como se ele fosse o próprio diamante, vai mostrando em cada face (em cada olhar) os diferentes sentimentos, tendências, atitudes, estados de ânimo e disposições reconhecíveis no ser humano como um todo (mas, ao mesmo tempo, dentro de sua necessária subjetividade).

Para exprimir passividade, absentismo, o narrador clariceano usa a expressão "olhando pela janela". Assim, por exemplo, ele descreve a volta de Ana, personagem do conto "Amor", a sua vida rotineira: "Depois, quando todos foram embora e as crianças já estavam deitadas, ela era uma mulher bruta que olhava pela janela" (LISPECTOR, 1998, p. 28-29).

O mesmo é exigido da personagem Laura, a fim de que sua "sanidade" seja validada: “Mas agora ela estava de novo 'bem', tomariam o ônibus, ela olhando como uma esposa pela janela, o braço no dele, e depois jantariam com Carlota e João, recostados na cadeira com intimidade" (LISPECTOR, 1998, p. 34).

Para exprimir complacência, Clarice escreve, por exemplo:

E Armando? Armando a olharia com um pouco de bom espanto - pois é essencial não esquecer que de forma alguma ele está sabendo que a empregada levou de tarde as rosas! Armando encararia com benevolência os impulsos de sua pequena mulher, e de noite eles dormiriam juntos (LISPECTOR, 1998, p. 45).

A autora também não esquece de usar a expressão "desviar os olhos" para exprimir vergonha, ou "piscar os olhos" para a desconfiança ou o desprezo, ou "entreolhar-se" para a cumplicidade, nem de lembrar que a liderança exige um "olhar autoritário".

Como já foi assinalado, para atingir esses efeitos, Clarice faz um uso bem particular dos recursos oferecidos pela linguagem - seu instrumento de trabalho - que define, no final das contas, seu estilo poético individual. Ora, não é por acaso que a linguagem utilizada por Clarice se torna confusa e, para alguns, até hermética: é que ela não é mais que o reflexo dessa confusão de sentidos, dessa cenestesia, desse tipo de conhecimento original, ao qual acompanha com extrema e difícil coerência. É o que Alfredo Bosi define como "a agudeza 
quase dolorosa da atenção, a linguagem escavada no sujeito que percebe o objeto e se percebe no objeto" (BOSI, 1975, p. 20).

Desse ponto de vista, o trabalho de Clarice (que também pintava) assemelha-se ao do pintor, que, segundo Merleau-Ponty, "é o único que tem direito de olhar para todas as coisas sem nenhum dever de apreciação. Dir-se-ia que, diante dele, as palavras de ordem do conhecimento e da ação perdem sua virtude" (MERLEAU-PONTY, 1980, p. 86).

E em seu trabalho, ela parece aplicar radicalmente a concepção de funcionamento da linguagem assinalada por Merleau-Ponty, segundo a qual

\begin{abstract}
a significação anima a palavra, como o mundo anima meu corpo, graças a uma surda presença que desperta minhas intenções, sem desdobrar-se diante delas. A intenção significativa em mim (como também no ouvinte que a reencontra ao me escutar), mesmo que deva em seguida frutificar em "pensamentos", no momento é apenas um vazio determinado a ser preenchido pelas palavras - o excesso do que quero dizer sobre aquilo que é ou já foi dito (MERLEAUPONTY, 1980, p. 135).
\end{abstract}

Por isso, Clarice Lispector parece inaugurar um novo leque de significações possíveis a partir de sua experiência com a palavra, tornando essa palavra, além de lírica, filosófica.

Pois bem, a intenção significativa de nossa autora é a que determina, na construção dos contos, a sua estrutura, na qual o olhar adquire uma importância singular. Com efeito, todo o volume de Laços de família é permeado de expressões alusivas ao olhar, aos olhos, à visão, à cegueira, etc., sendo que muitas proposições que contêm essas expressões têm a função de abrir novas seqüências dentro da narrativa. Algumas delas chegam, inclusive, a mudar radicalmente o rumo da história. Exemplos claros disso são as seguintes frases colhidas de alguns contos de a obra supracitada:

Foi então que olhou para o homem parado no ponto. [...] Era um cego" (LISPECTOR, 1998, p. 21).

Como era rica a vida comum, ela enfim voltara da extravagância. Até um jarro de flores. Olhou-o (LISPECTOR, 1998, p. 42).

Desta vez, quando o tira sem pressa, as pupilas estão extremamente doces e cansadas, e antes dele enxugar-se - eu vi. Vi a lágrima (LISPECTOR, 1998, p. 78).

Catarina viu então que sua mãe estava envelhecida e tinha os olhos brilhantes (LISPECTOR, 1998, p. 96).

Atrás do vidro escuro estava um rosto branco olhando-os (LISPECTOR, 1998, p. 114).

De fato, a própria obra, em seu conjunto, começa com uma alusão ao olhar: o primeiro conto da coletânea começa desta forma: "Pelo quarto parecia-lhe estarem a se cruzar os elétricos, a estremecerem-lhe a imagem refletida" (LISPECTOR, 1998, p. 9). 


\section{Algumas reflexões finais}

A vida humana é sempre limitada por barreiras sociais que são deflagradas e transgredidas em um plano sensorial, sobretudo através desse olhar múltiplo. No final, porém, acabam persistindo com uma tal insistência que, no fim das contas, o que Clarice parece querer nos dizer é que elas fazem parte integral e inevitável da condição humana. Elas funcionam como muletas que sustentam nosso difícil e precário equilíbrio existencial, conferindo uma sensação de estabilidade. E caso a pessoa não consiga ater-se a elas, estará fatalmente fadada à loucura, única saída possível.

O desencadeamento de uma crise, em função da tomada de consciência, por parte do sujeito, dessa situação (ou mesmo condição) existencial, conduz a um estado temporário de loucura. Como vimos, esse processo de conscientização é promovido e acionado por uma percepção corporal e sensorial do mundo. Ora, essa loucura, que representa o excesso, constitui a prova última da fragilidade dessa construção humana (social) de equilíbrio. É isso o que acontece com a personagem Laura, de "A imitação da rosa", que, não por acaso, ao descobrir-se de novo "doente", confessa a seu marido, desculpando-se: "Não pude impedir, repetiu entregando-lhe com alívio a piedade que ela com esforço conseguira guardar até que ele chegasse. Foi por causa das rosas, disse com modéstia” (LISPECTOR, 1998, p. 78-79).

É nesse sentido que o olhar (como os sentidos em geral) revela-se um importante instrumento de transformação. Um olhar renovado e renovador que, abolindo a infranqueável separação entre sujeito e objeto, permita a (re)aproximação de uma natureza tida como superior, nos contos de Clarice Lispector, em relação à cultura. É que essa natureza, redescoberta através de uma epifania (que antecede imediatamente a tomada de consciência referida acima), revela-se como um mundo onde tudo tem um sentido mais imediato, onde cada ser cumpre o seu papel de acordo com um compromisso que é unicamente com a vida. Isso é o que, de fato, verifica a principal personagem do conto "O búfalo" ao descobrir com espanto a harmonia da vida animal e também Ana, do conto "Amor", quando, no Jardim Botânico, observa:

Inquieta, olhou em torno. Os ramos se balançavam, as sombras vacilavam no chão. Um pardal ciscava na terra. E de repente, com mal-estar, pareceu-lhe ter caído numa emboscada. Fazia-se no Jardim um trabalho secreto do qual ela começava a se aperceber.

Nas árvores as frutas eram pretas, doces como mel. [...] No tronco da árvore pregavam-se as luxuosas patas de uma aranha. A crueza do mundo era tranqüila. $\mathrm{O}$ assassinato era profundo. E a morte não era o que pensávamos (LISPECTOR, 1998, p. 24-25).

Clarice mostra, ao mesmo tempo em que denuncia a prisão da existência humana, a limitação do pensamento discursivo (e, conseqüentemente, da linguagem comum a serviço 
dele) para a apreensão de determinadas realidades ou verdades mais sutis. Só através de muitas estratégias de elaboração pode alcançar a dizer, indiretamente - isso sim - aquilo que é essencial para o ser humano, seu mundo interior, sua realidade mais viva. Como vimos, utiliza - entre outros recursos - uma linguagem sensorial em que o corpo assume um papel protagônico. De fato, não estamos acostumados a deparar-nos com essa linguagem ou a fazer uso dela, pois a indefinição na linguagem também é um perigo, também pode levar ao desequilíbrio. Isso é o que rapidamente percebe Marcel Pretre ao se deparar com "A menor mulher do mundo":

\begin{abstract}
Na certa, apenas por não ser louco, é que sua alma não desvairou nem perdeu os limites. Sentindo necessidade imediata de ordem, e de dar nome ao que existe, apelidou-a de Pequena Flor. E, para conseguir classificá-la entre as realidades reconhecíveis, logo passou a colher dados a seu respeito (LISPECTOR, 1998, p. 69).
\end{abstract}

Assim, consideramos ter apresentado, ao menos sucintamente, alguns dos recursos que Clarice Lispector utiliza para explorar as múltiplas possibilidades do olhar na narrativa e, mais especificamente, em seus contos.

\title{
Referências
}

BAKHTIN, Mikhail. Questões de Literatura e Estética. São Paulo: Hucitec, 1988.

BOSI, Alfredo. O conto brasileiro contemporâneo. São Paulo: Cultrix/EDUSP, 1975.

CORTÁZAR, Julio. Valise de Cronópio. São Paulo: Debates, 1974.

GALVÃO, Walnice Nogueira. Cinco teses sobre o conto. In: O Livro do Seminário. São Paulo: L R Editores Ltda., 1982.

GOTLIB, Nádia Battella. Clarice. Uma vida que se conta. São Paulo: Ática S.A., 1995.

HOHLFELDT, Antonio Carlos. Conto brasileiro contemporâneo. Porto Alegre: Mercado Aberto, 1988.

LISPECTOR, Clarice. Laços de família. Rio de Janeiro: Rocco, 1998.

LUCAS, Fábio. O conto no Brasil moderno. In: O Livro do Seminário. São Paulo: L R Editores Ltda., 1982.

LYOTARD, Jean-François. A Fenomenologia. Lisboa: Edições 70, 1986.

MERLEAU-PONTY, Maurice. Fenomenologia da linguagem. In: Os Pensadores. São Paulo: Abril Cultural, 1980. . O olho e o espírito. In: Os Pensadores. São Paulo: Abril Cultural, 1980. 
NUNES, Benedito. O drama da linguagem. Uma leitura de Clarice Lispector. São Paulo: Ática, 1989.

PIGLIA, Ricardo. O Laboratório do Escritor. São Paulo: Iluminuras, 1994.

SIMON, Cátia Castilho. Clarice Lispector sob suspeita. In: Sociologias, ano 1, n.1, jan/jun. Porto Alegre: PPGS/UFRGS, 1999. 